\title{
CONCENTRATION-DEPENDENT EFFECTS OF NEOSTIGMINE ON THE ENDPLATE ACETYLCHOLINE RECEPTOR CHANNEL COMPLEX ${ }^{1}$
}

\author{
JEROME F. FIEKERS \\ Department of Anatomy and Neurobiology, The University of Vermont College of Medicine, Burlington, Vermont 05405
}

Received June 14, 1984; Revised August 22, 1984; Accepted August 27, 1984

\begin{abstract}
The concentration-dependent actions of neostigmine, a carbamate anticholinesterase agent, were studied on the acetylcholine receptor channel complex in voltage-clamped twitch fibers of costocutaneous muscles of garter snakes. Low concentrations of neostigmine $\left(10^{-6}\right.$ or $\left.10^{-5} \mathrm{M}\right)$ increased miniature endplate current (MEPC) amplitude and the time constant of MEPC decay without changing the relationship between the MEPC decay time constant and membrane potential. Acetylcholine- or carbachol-induced endplate current fluctuation spectra were well fitted by a single Lorentzian curve with a characteristic frequency and singlechannel conductance unaltered by low concentrations of neostigmine. Concentrations of neostigmine greater than $5 \times 10^{-5} \mathrm{M}$ decreased MEPC amplitude and split the decay of MEPCs into two components, one faster and one slower than the control rate. These effects were both voltage and concentration dependent. Spectra of current fluctuations recorded in concentrations $\geq 5 \times 10^{-5} \mathrm{M}$ neostigmine required two time constants, one faster and one slower than the control. Two component spectra were also obtained with carbachol-induced current fluctuation spectra, indicating that these effects of neostigmine were direct and not a consequence of acetylcholinesterase inhibition. Similar results were also obtained in muscles pretreated with collagenase to remove junctional acetylcholinesterase. The fast and slow time constants obtained from current fluctuation spectra decreased and increased, respectively, with either increases in the concentration of neostigmine or membrane hyperpolarization when analyzed in the same fiber. The effects of neostigmine on channel lifetime were reversible with washing. These results indicate that the effects of neostigmine are concentration dependent. Concentrations $>2.5 \times 10^{-5} \mathrm{M}$ exhibit direct effects on the endplate receptor channel complex which are unrelated to acetylcholinesterase inhibition. These actions include: (1) a prolongation of the gating kinetics of the endplate receptor channel complex, (2) the production of an altered state of the receptor channel complex evidenced by a high frequency component to current fluctuation spectra, and (3) a direct action to block the acetylcholine receptor.
\end{abstract}

Acetylcholine $(\mathrm{ACh})$ released from the nerve terminal into the synaptic cleft of the motor endplate is subject to three main processes: (1) attachment to specific endplate receptors leading to a transient opening of ion gates, (2) attachment to acetylcholinesterase (AChE) leading to the hydrolysis of $\mathrm{ACh}$, and (3) diffusional spread leading to escape from the synaptic cleft. These processes occur almost simultaneously, each, however, with its own respective rate. Hydrolysis of $\mathrm{ACh}$ by the activity of $\mathrm{AChE}$ is the primary mechanism for the termination of transmitter action in the synaptic cleft (Magleby and Stevens, 1972a; Rosenberry, 1979; Wathey et. al., 1979; Adams, 1981). Poisoning of AChE by anticholinesterase agents has been widely used experimentally to explore the role esterase activity plays in the normal functioning of cholinergic synapses. Anticholinesterases are also frequently used clinically, most notably in the symptomatic treatment of myasthenia gravis to increase the cleft concentration of transmitter and thereby facilitate neuromuscular transmission.

Inhibiting the activity of AChE prolongs the duration of endplate potentials (EPPs) (Feng, 1940; Eccles et al., 1942;

\footnotetext{
1 'T'his work was supported by a Muscular Dystrophy Association grant and by National Science Foundation Grant BNS81-10974.
}

Eccles and MacFarlane, 1949; Fatt and Katz, 1951), miniature endplate currents (MEPCs) (Gage and McBurney, 1975), and endplate currents (EPCs) (Takeuchi and Takeuchi, 1959; Kordas, 1968, 1972a; Magleby and Stevens, 1972a; Kuba et al., 1974; Goldner and Narahashi, 1974; Pascuzzo et al., 1984). The prolonged time course of the synaptic recordings was considered a reflection of the prolonged duration of the cleft concentration of ACh, a consequence of AChE inhibition. This was substantiated by Katz and Miledi (1975), who demonstrated by using fluctuation analysis that prostigmine had no effect on the mean channel lifetime and suggested that the prolonged EPC decay was due to delayed diffusion of $\mathrm{ACh}$ from the synaptic cleft resulting from repeated binding of $\mathrm{ACh}$ to the endplate receptors. However, in addition to the indirect effects (enzyme inhibition) of anticholinesterase agents, direct actions of these agents have also been reported. These include: (1) a reduction in the amplitude of EPPs (Eccles and MacFarlane, 1949; Kuba and Tomita, 1971), MEPCs (Gage and McBurney, 1975), and EPCs (Magleby and Stevens, 1972a, b; Magleby and Terrar, 1975); (2) direct actions on the ACh receptor channel complex to prolong the decay of postsynaptic currents (Magleby and Stevens, 1972a, b; Kordas et al., 1975; White and Gardner, 1983; Pascuzzo et al., 1984); (3) a direct action to block open 
ACh receptor channel complexes (Kuba et al., 1974); and (4) a direct effect to modify the kinetics of open endplate channels and produce receptor desensitization (Akaike et al., 1984; Pascuzzo et al., 1984). Numerous reports have also demonstrated a presynaptic effect of anticholinesterase agents (Miyamoto, 1978; Duncan and Publicover, 1979; Alderdice, 1982). Few reports have studied the electrophysiological effects of anticholinesterases over a wide concentration range. Due to the importance of anticholinesterases in experimental and clinical applications, the present series of experiments was undertaken to distinguish between indirect effects of $\mathrm{AChE}$ inhibition and direct effects on the ACh receptor channel complex. The concentration-dependent actions of neostigmine were studied on MEPCs and agonist-induced EPC fluctuations. The present results demonstrate that neostigmine has direct actions on the ACh receptor channel complex which are separate and distinct from its well known effects due to AChE inhibition. Neostigmine (1) prolongs the kinetics of $\mathrm{ACh}$ receptor channel gating, (2) produces a modified state of the $\mathrm{ACh}$ receptor channel complex evidenced by the presence of a high frequency component to current fluctuation spectra, (3) inhibits the activity of $\mathrm{AChE}$, and (4) produces a block of the ACh receptor. A preliminary report of some of these findings has been presented (Fiekers, 1983a).

\section{Materials and Methods}

Costocutaneous muscles of garter snakes (Thamnophis) were dissected with a section of the rib and scale into which they were inserted and mounted in a glass-bottomed Plexiglas chamber. The preparation was bathed in a physiological salt solution of the following composition (millimolar concentration): $\mathrm{NaCl}, 159 ; \mathrm{KCl}, 2.15 ; \mathrm{CaCl}_{2}, 1.0 ; \mathrm{MgCl}_{2}$, 4.2; HEPES ( $N$-(2-hydroxyethyl)piperazine- $N^{\prime}$-2-ethanesulfonic acid), $1.0 ; \mathrm{pH} 7.2$. All experiments were carried out at $19.50^{\circ} \mathrm{C}$. The temperature of the bath was maintained by a bipolar controlled Peltier heating/cooling stage (Cambion Division, Cambridge, MA) which maintained the bath temperature within $\pm 0.2^{\circ} \mathrm{C}$.

MEPCs and agonist-induced EPC fluctuations were recorded from individual twitch fiber endplates with a two-microelectrode voltage clamp circuit similar to that described by Dionne and Stevens (1975) with two modifications: (1) the high voltage current stages were replaced with low voltage $( \pm 15 \mathrm{~V})$ equivalents, and $(2)$ the membrane voltage was measured differentially between the intracellular voltage electrode and a bath ground independent of the current electrode. Membrane current was monitored as the voltage drop across a 1megohm resistor in series with the current-measuring microelectrode. 'The voltage and current microelectrodes were filled with $3 \mathrm{M} \mathrm{KCl}$ and had resistances of 5 to 10 megohms when measured in normal physiological solution. The electrodes were placed intracellularly under direct visual control approximately $50 \mu \mathrm{m}$ apart on either side of the fiber endplate with the aid of a dynoptic microscope adapted with Hoffman modulation contrast optics (Modulation Optics, Inc., Greenvale, NY). Twitch fiber endplates of garter snakes are compact, situated approximately 60 to $70 \mu \mathrm{m}$ along the fiber and composed of clusters of boutons (Hess, 1965; Kuffler and Yoshikami, 1975). Because of the long space constant and small receptor area, the postsynaptic membrane of twitch fibers can be efficiently voltage clamped with the two-microelectrode technique. The voltage clamp feedback gain varied with the frequency and was adjusted for each fiber as high as possible without ringing. Membrane voltage was well controlled, and for each recorded MEPC the voltage transient was simultaneously measured. At the peak of the MEPC, this transient was $<0.1 \%$ of the net driving force $(V-V r)$, where $V$ is the membrane potential and $V r$ is the transmitter reversal potential.

Either ACh or carbachol (CCh) was applied iontophoretically to visually identified junctional regions of muscle fibers using a constant current feedback circuit (Dionne, 1976). The iontophoretic current was determined from the voltage drop across a 1-megohm resistor in series with the iontophoretic electrode. Electrodes were filled with either 1 or $2 \mathrm{M}$ of either agonist. A braking current was applied to the electrode of an appropriate value determined by advancing the microelectrode slowly toward the muscle surface. If any depolarization or change in the holding current occurred, then the braking current was increased until no change was detected with the iontophoretic electrode immediately above the endplate region. Care was taken following neostigmine to remain in the low concentration limit for $\mathrm{ACh}$ and $\mathrm{CCh}$ by restricting mean induced EPCs to less than $20 \mathrm{nA}$. Current records (MEPCs and EPC fluctuations) were recorded digitally at an appropriate gain with a laboratory computer, stored on floppy disks, and subsequently analyzed as described previously (Fiekers, 1983b).

In the presence of high concentrations of neostigmine, MEPCs frequently required the sum of two exponentials to fit the decay phase properly. The amplitudes and rate constants for the respective components were determined using a computerized double exponential fitting program described in detail previously (Connor et al., 1983).

The spectral density of the fluctuations recorded in control solution and in low concentrations of neostigmine could be adequately fit with a single Lorentzian function. Mean channel lifetime, $\tau$, was obtained from the corner frequency, $f_{o}$, using the relation

$$
\tau_{\eta}=1 / 2 \pi f_{o}
$$

Mean single-channel conductance $(\gamma)$ was estimated in several ways. (1) The root mean square amplitude of the EPC and its mean value, $\bar{u}$, were recorded. The root mean square record was squared and corrected for background noise to obtain the total induced variance, $\sigma$, and $\gamma$ was estimated as

$$
\bar{\gamma}=\sigma / \bar{u}(V-V r)
$$

(2) $\gamma$ was also estimated by fitting a single Lorentzian to the spectra and using the following expression

$$
\bar{\gamma}=S(0) \pi f_{o} / 2 \bar{u}(V-V r)
$$

where $S(0)$ represents the zero frequency amplitude.

Values of $\gamma$ obtained by these methods differed by only a few percent.

Power density spectra obtained in the presence of high concentrations of neostigmine required the sum of two Lorentzian components for a proper fit. The two component spectra were fit according to the following relation

$$
S(f)=S_{1}(0) /\left[1+\left(2 \pi f / \alpha_{1}\right)^{2}\right]+S_{2}(0) /\left[1+\left(2 \pi f / \alpha_{2}\right)^{2}\right]
$$

where $S_{1}$ and $S_{2}$ represent the zero frequency amplitudes of each spectral component, and $\alpha_{1}$ and $\alpha_{2}$ represent the corresponding rates.

For some experiments muscles were pretreated with collagenase to inactivate the junctional esterase as described previously (Betz and Sakmann, 1971, 1973; Hall and Kelly, 1971). Whole muscle mounts were perfused with $0.2 \%$ collagenase (Type $1 \mathrm{~A}$ Collagenase; Sigma Chemical Co., St. Louis, MO) for approximately $2 \mathrm{hr}$. Following this treatment, the muscles were washed for $30 \mathrm{~min}$ with normal physiolog. ical solution.

To assess the extent of enzyme inhibition produced by the collagenase treatment and neostigmine concentrations in the bath, esterase activity was determined qualitatively using the histochemical procedures similar to those previously described (Koelle and Friedenwald, 1949).

Concentrated stock solutions of neostigmine bromide (Sigma Chemical Co.) were made up every 2 to 3 days and diluted daily to the desired concentration. The bath was connected serially to a perfusion pump (Holter 911, Extracorporeal Medical Specialties, Inc., King of Prussia, PA), enabling the bath solution to be changed quickly. In this way, known concentrations of neostigmine could be quickly applied to the preparation and several concentrations of the drug could be examined in the same voltage-clamped fiber. The preparation was allowed to equilibrate for $20 \mathrm{~min}$ following each solution change. Only surface fibers of the preparation were used for recording, and these were equilibrated rapidly following a solution change. All average values cited in the text and the tables are means $\pm \mathrm{SD}$, with the number of fibers in parentheses. All $p$ values $\leq 0.05$ are considered statistically significant.

\section{Results}

Low concentrations of neostigmine prolong $M E P C$ decay without altering channel lifetime. Concentrations of neostigmine up to and including $10^{-5} \mathrm{M}$ increased the amplitude and the time constant of MEPC decay in a concentration-dependent manner. Figure 1 illustrates MEPCs recorded in a single fiber voltage clamped to $-80 \mathrm{mV}$ before (Fig. $1 A$ ) and after $25 \mathrm{~min}$ 
A
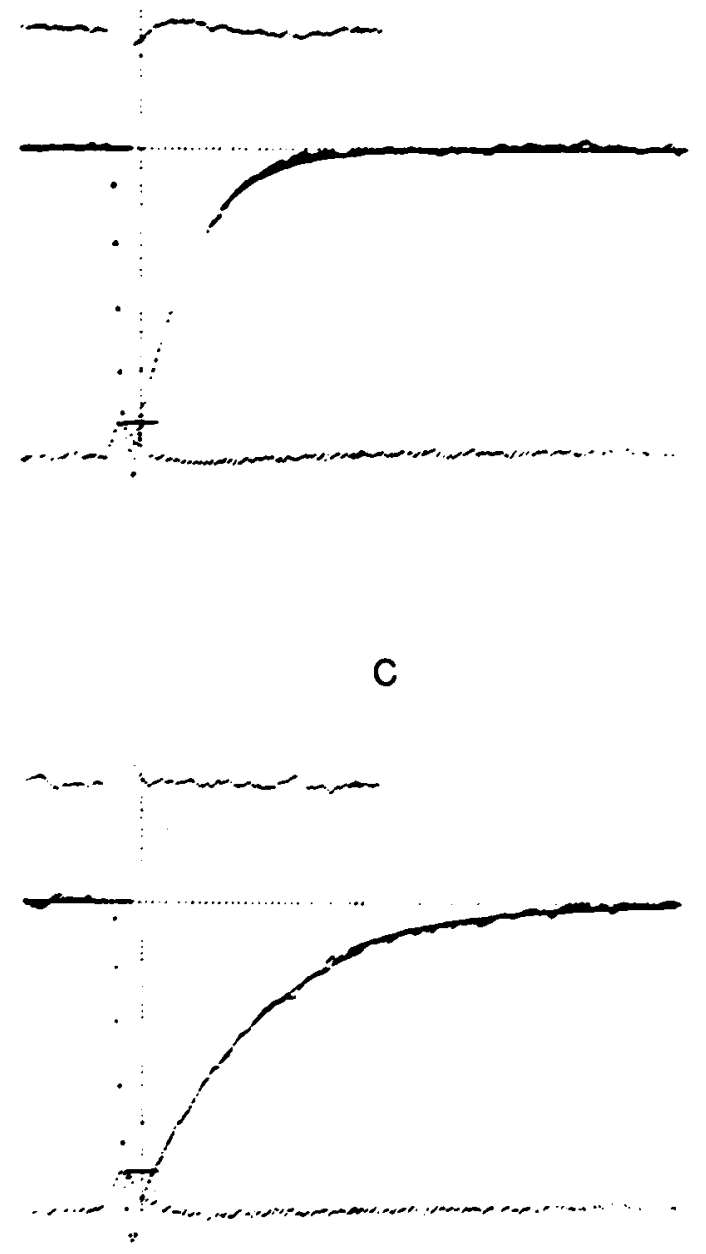

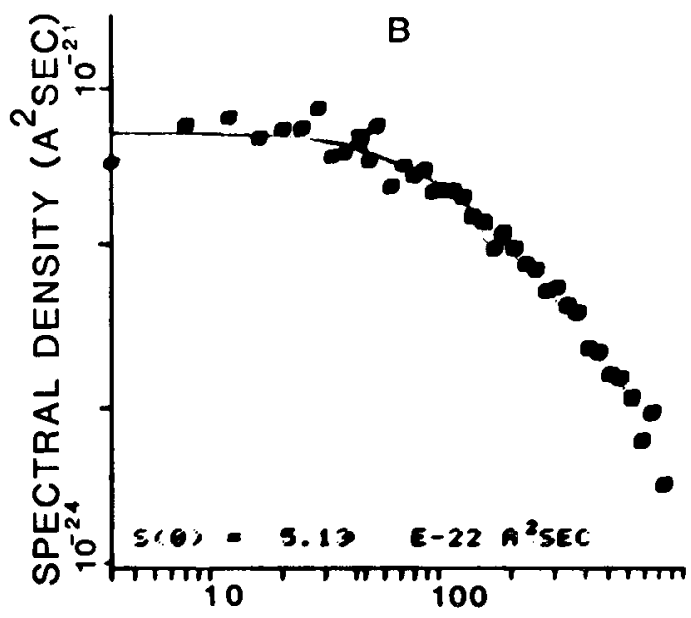

FREQUENCY (Hz)

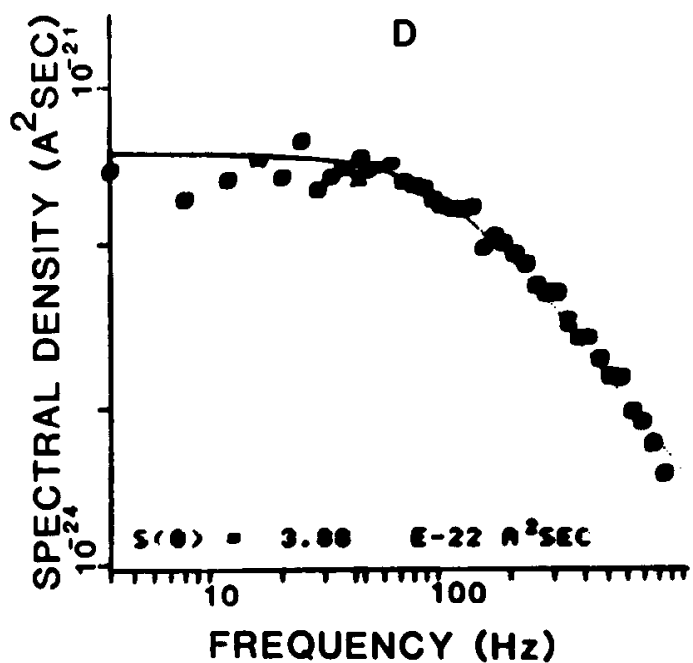

Figure 1. MEPCs and a power density spectrum of $\mathrm{ACh}$-induced current fluctuations recorded from a single fiber voltage clamped at $-80 \mathrm{mV}$ in control solution $(A$ and $B)$ and in $10^{-5} \mathrm{M}$ neostigmine $(C$ and $D) . A$ is an average of $20 \mathrm{MEPCs}$ recorded in control solution. Peak MEPC amplitude was $-5.34 \mathrm{nA}$ and the decay rate was $0.53 \mathrm{msec}$, corresponding to a decay time constant of $1.88 \mathrm{msec}$. The top line in each $\mathrm{MEPC}$ record is the difference at high gain between the theoretical fit and the experimental data. A good fit to the data would be represented by a straight line. The middle trace is the digitized MEPC trace with a theoretical best fit to the data superimposed. The bottom trace is the voltage deviation recorded at 1000 to 2000 gain during the peak of the MEPC. $B$, A plot of current fluctuations with a corner frequency $\left(f_{o}\right)$ of $94 \mathrm{~Hz}$, with a time constant of $1.69 \mathrm{msec}$ and a zero frequency amplitude of $5.13 \times 10^{-22} \mathrm{~A}^{2} \mathrm{sec}$. $C$, An average of $20 \mathrm{MEPCs}$ recorded in $10^{-5} \mathrm{M}$ neostigmine; peak MEPC amplitude was $-5.89 \mathrm{nA}$, and the decay rate was $0.218 \mathrm{msec}$ with a corresponding time constant of $4.59 \mathrm{msec}$. This represents a 2.4-fold increase in the MEPC decay time constant. $D$, A spectral density plot of current fluctuations recorded in $10^{-5} \mathrm{M}$ neostigmine. The corner frequency was $102 \mathrm{~Hz}$ corresponding to a time constant of $1.56 \mathrm{msec}$, and the zero frequency amplitude was $3.88 \times 10^{-22} \mathrm{~A}^{2}$ sec. The dotted lines in the power spectral curves represent each spectral component.

TABLE I

Concentration-dependent actions of neostigmine on spontaneously occurring MEPCs and noise characteristics

\begin{tabular}{|c|c|c|c|c|c|}
\hline & $\begin{array}{c}\text { MEPC } \\
\text { Amplitude } \\
(\mathrm{nA})^{a}\end{array}$ & $\begin{array}{c}\tau_{\text {mepe }} \\
\text { (msec) }\end{array}$ & $\begin{array}{c}\text { Corner Frequency } \\
(\mathrm{Hz})\end{array}$ & $\begin{array}{c}\tau_{n} \\
\text { (msec) }\end{array}$ & $\begin{array}{c}\gamma \\
(\mathbf{p s})^{b}\end{array}$ \\
\hline Control & $-3.8 \pm 1.3$ & $2.1 \pm 0.6$ & $74 \pm 18$ & $2.2 \pm 0.6$ & $31.9 \pm 3.0$ \\
\hline
\end{tabular}

\footnotetext{
${ }^{a}$ Data are mean $\pm \mathrm{SD}$ recorded from at least six fibers of each concentration at $-80 \mathrm{mV}$ and $19.5^{\circ} \mathrm{C}$.
}

${ }^{b} \mathrm{ps}$, picosiemen; determined from variance of EPC fluctuations.

${ }^{c}$ Four fibers listed here had single Lorentzian shapes; five others required two time constants. 


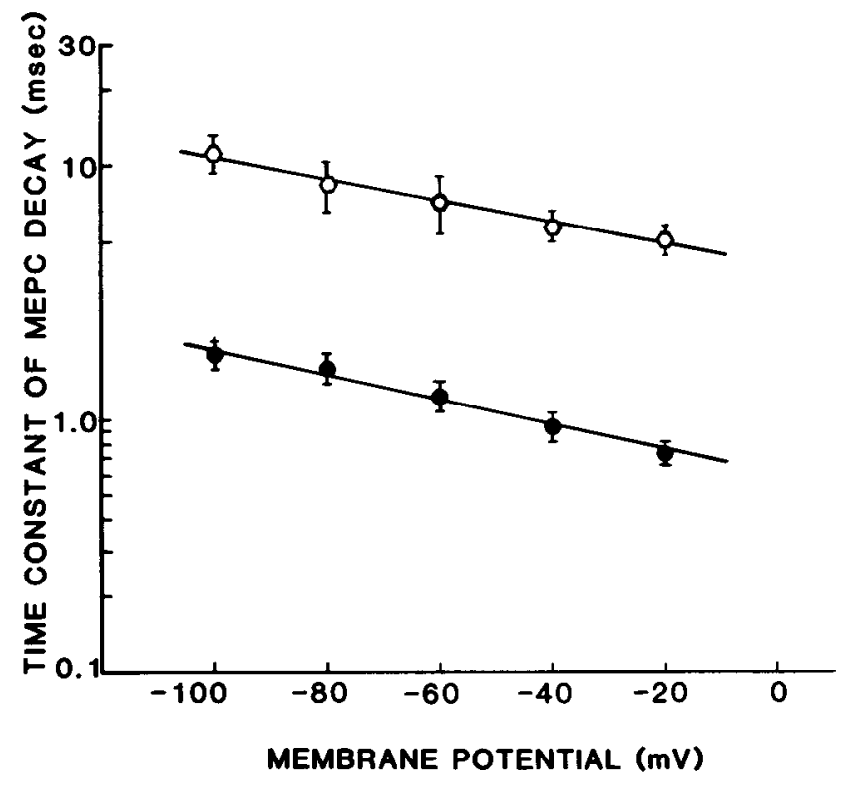

Figure 2. Voltage dependence of the time constant of MEPC decay. The natural logarithm (ln) of the time constant of MEPC decay is plotted versus membrane potential for fibers in control solution (๑) and in $10^{-5} \mathrm{M}$ neostigmine $(\mathrm{O})$. Each point represents the mean value of at least four fibers (20 MEPCs/fiber) in which MEPCs were recorded over a wide voltage range. The solid lines were drawn according to equation 5 for both sets of data. For the control relation: $\tau(0)=0.45 \pm$ $0.26 \mathrm{msec} ; A=-0.0106 \pm 0.0035 / \mathrm{mV}$; for neostigmine: $\tau(0)=1.27 \pm$ $0.14 \mathrm{msec} ; A=-0.0110 \pm 0.0030 / \mathrm{mV}$.

in $10^{-5} \mathrm{M}$ neostigmine (Fig. $1 \mathrm{C}$ ). In 32 control experiments the mean time constant of MEPC decay was $2.09 \pm 0.57 \mathrm{msec}(-80$ $\mathrm{mV}, 19.5^{\circ} \mathrm{C}$ ). A 3.5-fold increase in the time constant of MEPC decay to $7.5+2.4 \mathrm{msec}(n=18)$ was obtained in $10^{-5} \mathrm{M}$ neostigmine. In $10^{-6}$ and $5 \times 10^{-6} \mathrm{M}$ neostigmine, the time constant of MEPC decay was increased 2.0- and 2.8-fold, respectively. These results are consistent with previous reports demonstrating a 2- to 3 -fold prolongation of EPC decay following neostigmine (Takeuchi and Takeuchi, 1959; Kordas, 1972a; Magleby and Stevens, 1972a; Katz and Miledi, 1973; Gage and McBurney, 1975; Magleby and Terrar, 1975). The mean lifetime of the endplate channels determined from the cut-off frequency of power spectral density curves was unchanged in concentrations of neostigmine up to and including $10^{-5} \mathrm{M}$ (Fig. 1; Katz and Miledi, 1973). Spectral density curves obtained in the same fiber as the recorded MEPCs were obtained before (Fig. $1 B$ ) and after (Fig. $1 D$ ) exposure to $10^{-5} \mathrm{M}$ neostigmine. The mean cut-off frequency in control solution was $74 \pm 18$ $\mathrm{Hz}$, yielding a time constant of $2.1 \pm 0.3 \mathrm{msec}(n=12)$. In $10^{-5}$ M neostigmine, $f_{o}$ was $81 \mathrm{~Hz}$, yielding a time constant of $1.9 \pm$ $0.5 \mathrm{msec}(n=5)$. These results demonstrate that in concentrations up to and including $10^{-5} \mathrm{M}$ neostigmine, power spectral density curves are adequately described by a single Lorentzian line shape with a characteristic frequency unchanged by neostigmine. The mean single-channel conductance also was not changed by neostigmine (see Table I).

Neostigmine does not alter the voltage dependence of $M E P C$ decay in low concentrations. The time constant of MEPC decay in control solutions depends on the value of the membrane potential. Hyperpolarization of the membrane increases the decay time constant of MEPCs, whereas depolarization decreases it (Magleby and Stevens 1972a, b; Gage and McBurney, 1975). The dependence of the time constant of MEPC decay (the reciprocal of the MEPC decay rate) on membrane potential can be described by the following relation

$$
\tau(V)=\tau(0) e-A V
$$

where $V$ is the membrane potential, $\tau(0)$ is the time constant of MEPC decay at $0 \mathrm{mV}$, and $A$ is the voltage dependence of $\tau$. Figure 2 demonstrates that neostigmine at a concentration of $10^{-5} \mathrm{M}$ does not alter the voltage dependence of the time constant of MEPC decay. The cocfficient of voltage depend-

MEMBRANE POTENTIAL (mV)

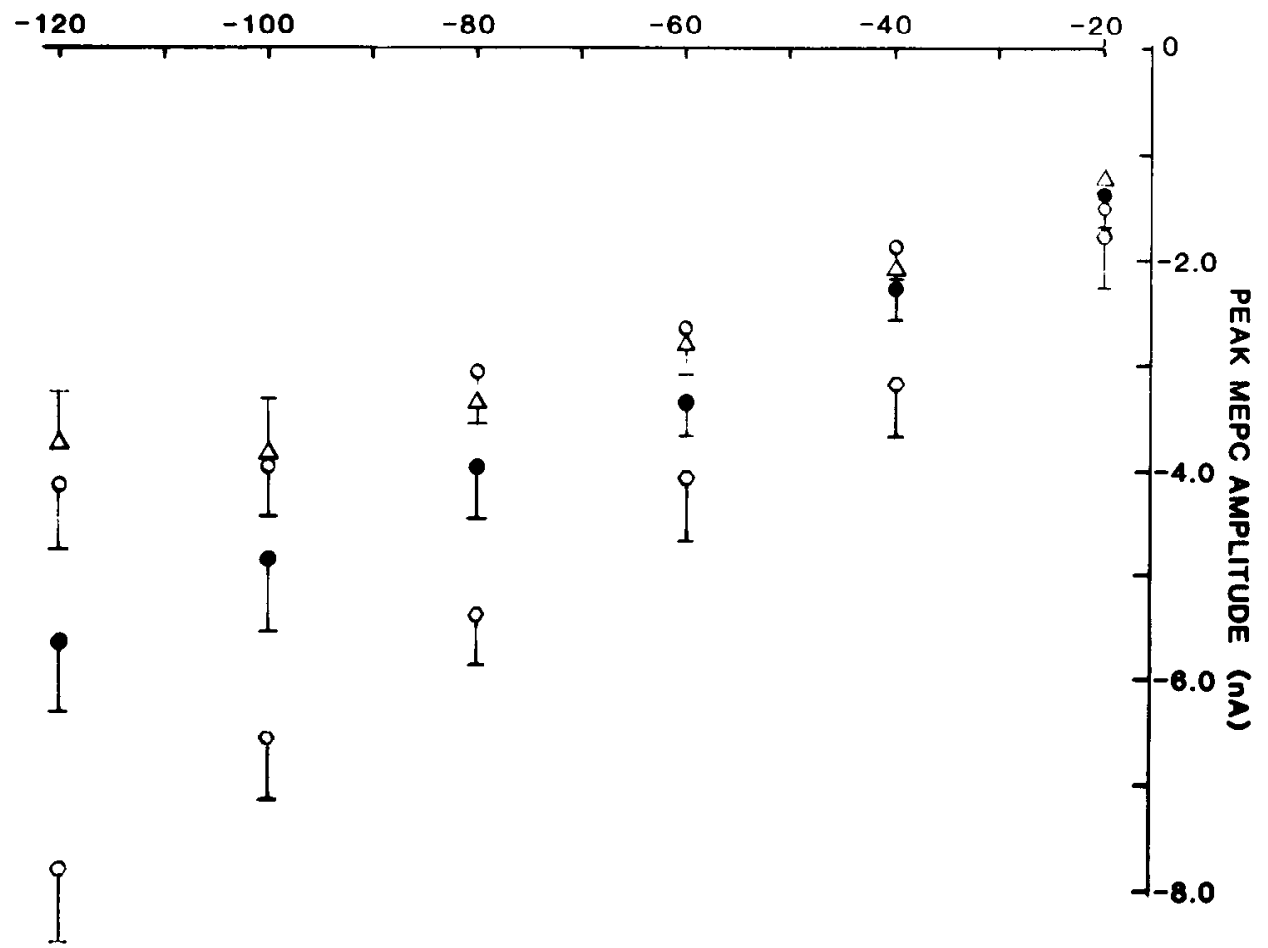

Figure 3. Peak current amplitude is plotted versus membrane potential for several concentrations of neostigmine. Each point represents the mean of seven fibers in which MEPCs were recorded uver a wide voltage range. Low concentrations, up to $10^{-5} \mathrm{M}$ neostigmine, increased peak MEPC amplitude, but higher concentrations consistently reduced peak MEPC amplitude. $\bullet$, control; $O, 10^{-5} \mathrm{M}$ neostigmine; $O, 5 \times 10^{-5} \mathrm{M}$ neostigmine; $\triangle, 10^{-4}$ $\mathrm{M}$ neostigmine. 
TABLE II

The effects of $5 \times 10^{-5} \mathrm{M}$ neostigmine on the fast and slow time constants of MEPC decay at several values of membrane potential

\begin{tabular}{|c|c|c|c|c|c|c|c|c|}
\hline & \multicolumn{2}{|c|}{ Fiber 1} & \multicolumn{2}{|c|}{ Fiber 2} & \multicolumn{2}{|c|}{ Fiber 3} & \multicolumn{2}{|c|}{ Fiber 4} \\
\hline & $\tau_{f}$ & $r_{s}$ & $\tau_{i}$ & $\tau_{s}$ & $\tau_{t}$ & $\tau_{s}$ & $\tau_{f}$ & $\tau_{s}$ \\
\hline & \multicolumn{8}{|c|}{$m s e c$} \\
\hline$-80 \mathrm{mV}$ & 1.8 & 8.1 & 3.9 & 5.6 & 2.1 & 7.5 & 2.3 & 6.2 \\
\hline$-103 \mathrm{mV}$ & 1.9 & 11.7 & 2.6 & 8.3 & 3.7 & 10.3 & 2.9 & 9.8 \\
\hline$-123 \mathrm{mV}$ & 4.3 & 14.4 & 3.9 & 10.4 & 4.0 & 13.2 & 4.3 & 13.3 \\
\hline
\end{tabular}

ence, $A$, (equation 5 ) in control solution was $-0.0106 \pm 0.0035 /$ $\mathrm{mV}$. In $10^{-5} \mathrm{M}$ neostigmine, $A$ was $-0.0109 \pm 0.0030 / \mathrm{mV}$. These values are not significantly different $(p<0.05)$ and are similar to previously reported control values for MEPCs reported from snake twitch fiber endplates (Dionne and Parsons, 1981; Fiek-

\section{A}

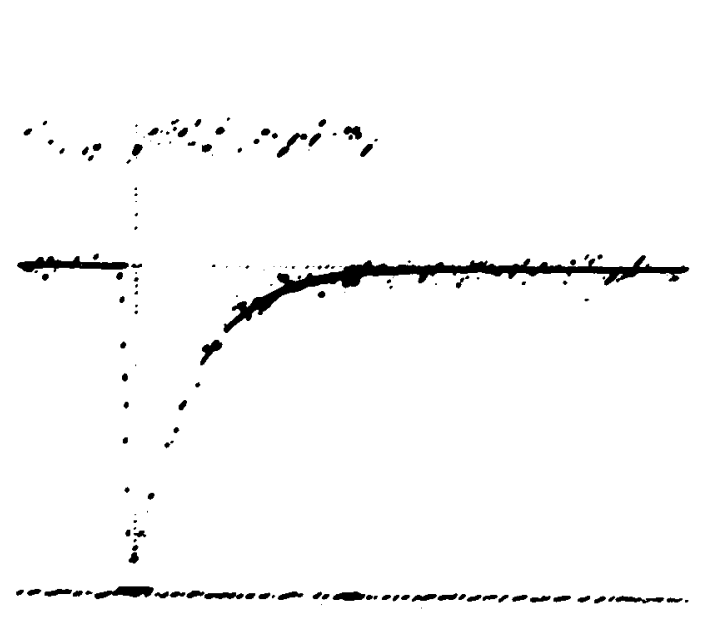

ers, 1983b). Although the voltage dependence of MEPC decay was unchanged in neostigmine, the rates of MEPC decay were considerably decreased as expected. The time constant of MEPC decay at $0 \mathrm{mV}, \tau(0)$, was increased 2.8 -fold in $10^{-5} \mathrm{M}$ neostigmine. Table I summarizes the effects of low concentrations of neostigmine on MEPCs and noise characteristics at the snake endplate.

Effects of neostigmine on peak current-voltage relationship. Concentrations of neostigmine up to $2.5 \times 10^{-5} \mathrm{M}$ increased the peak MEPC amplitude at all voltages studied. Concentrations above $2.5 \times 10^{-5} \mathrm{M}$, e.g., $5 \times 10^{-5} \mathrm{M}$, reduced the amplitude of MEPCs below control values at all membrane potentials. For example, at $10^{-5} \mathrm{M}$ neostigmine $(-80 \mathrm{mV})$, peak MEPC amplitude was increased $24 \%$ above control values. At $5 \times 10^{-5} \mathrm{M}$ neostigmine, mean MEPC amplitude was reduced below control values $14 \%$ at $-80 \mathrm{mV}$ and $31 \%$ at $-120 \mathrm{mV}$. These results
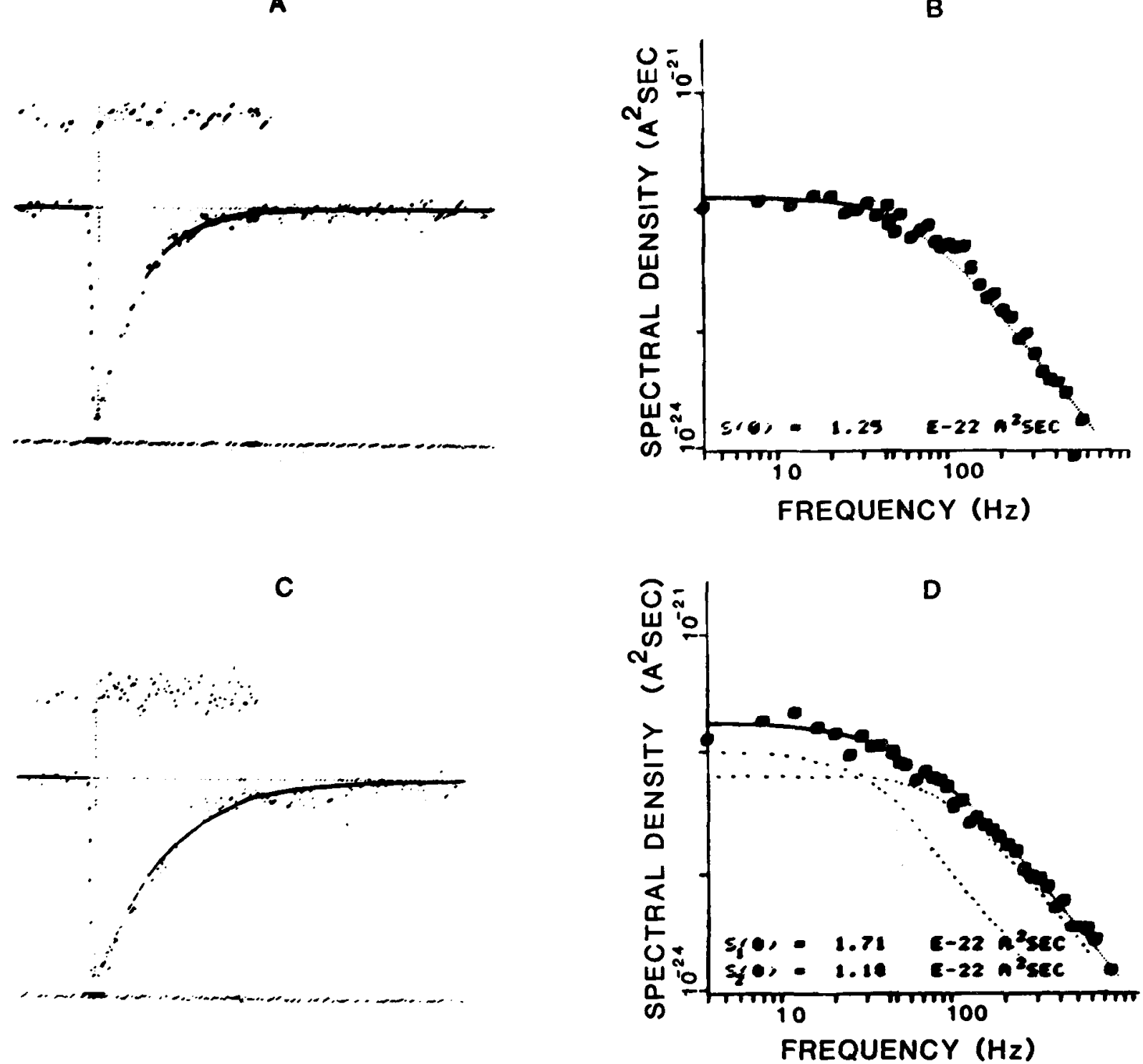

Figure 4. A, MEPCs and power density spectral curves recorded in the same fiber in control solution and in $5 \times 10^{-5} \mathrm{M}$ neostigmine. In control solution both MEPCs and power spectral density curves required one time constant. Peak MEPC amplitude was $-5.27 \mathrm{nA}$ and the decay rate was $0.458 \mathrm{msec}(\tau=2.18 \mathrm{msec})$; in $B$ the control spectrum had a cut-off frequency of $76 \mathrm{~Hz}$ with a time constant of 2.09 msec and a zero frequency amplitude of $1.25 \times 10^{-22} \mathrm{~A}^{2} \mathrm{sec}$. $C$ represents a mean MEPC recorded in the same fiber at $-80 \mathrm{mV}$ in $2.5 \times 10^{-5} \mathrm{M}$ neostigmine. Peak current amplitude was $-5.59 \mathrm{nA}$; the decay rate was $0.261 \mathrm{msec}$, corresponding to a time constant of 3.83 msec. Two-component spectra were obtained in concentrations of neostigmine greater than $10^{-5} \mathrm{M}$. The respective time constants required to fit these spectra represented two components, one faster and one slower than the control rate. For this fiber $(D), f_{1}=46 \mathrm{~Hz}$ with an amplitude of $1.71 \times 10^{-22} \mathrm{~A}^{2}$ sec, and $f_{2}=135 \mathrm{~Hz}$ with an amplitude of $1.18 \times 10^{-22} \mathrm{~A}^{2}$ sec. 


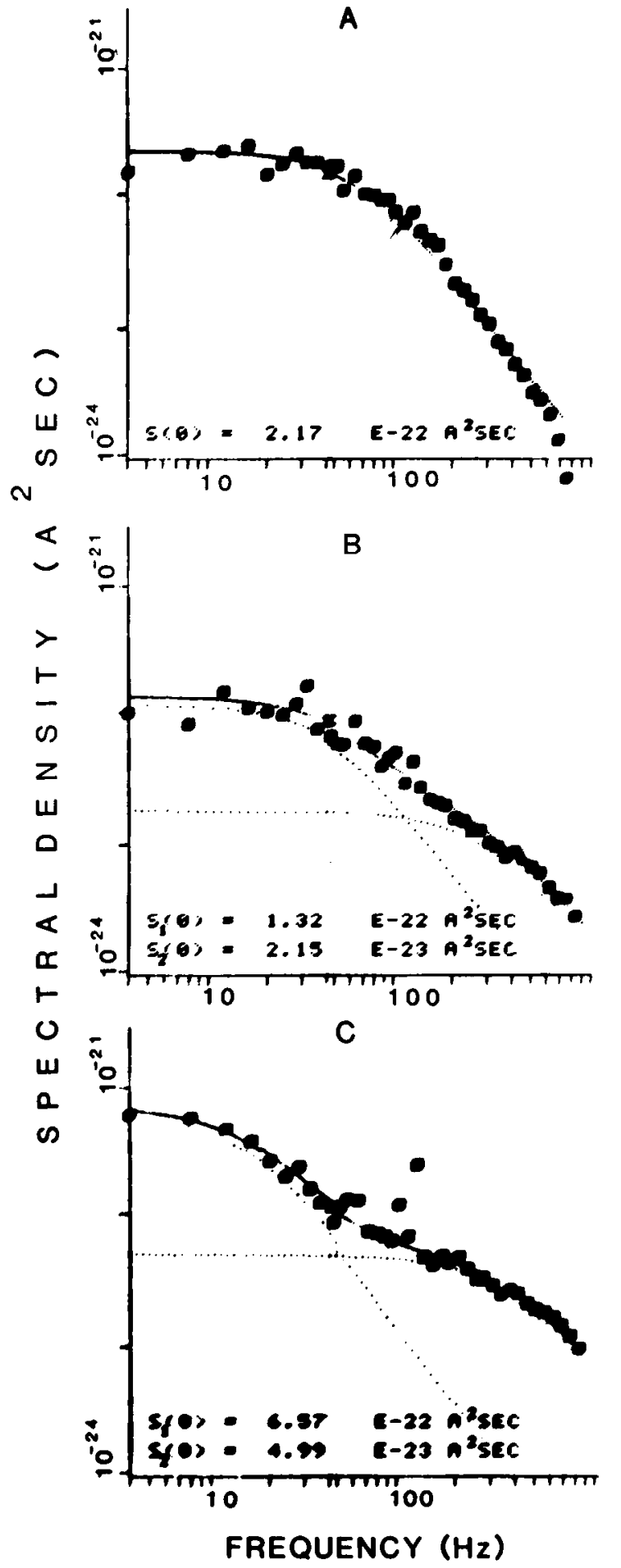

Figure 5. Spectral density curves recorded from the same fiber in control solution $(A)$ and in $5 \times 10^{-5} \mathrm{M}$ neostigmine $(B$ and $C)$. In control solution the spectra were well fit by a single Lorentzian line shape with $f_{o}=67 \mathrm{~Hz}$, corresponding to a time constant of $2.37 \mathrm{msec}$ and a zero frequency amplitude of $2.17 \times 10^{-22} \mathrm{~A}^{2}$ sec. $B$ and $C$ illustrate the effect of membrane hyperpolarization on the spectral shape. In $B$, recorded at $-80 \mathrm{mV}, f_{1}=48 \mathrm{~Hz}$ and $f_{2}=317 \mathrm{~Hz}$. The amplitude of each component was $1.32 \times 10^{-22} \mathrm{~A}^{2} \mathrm{sec}\left(f_{1}\right)$ and $2.15 \times 10^{-23} \mathrm{~A}^{2}$ sec. $I_{2} / I_{1}=0.16$. In $C$, recorded at $-120 \mathrm{mV}$, the cut-off frequency and zero frequency amplitudes were, respectively: $f_{1}=15 \mathrm{~Hz}, 6.84 \times 10^{-22} \mathrm{~A}^{2}$ sec, and $f_{2}=396 \mathrm{~Hz}, 5.41 \times 10^{-23} \mathrm{~A}^{2}$ sec. $I_{2} / I_{1}=0.08$.
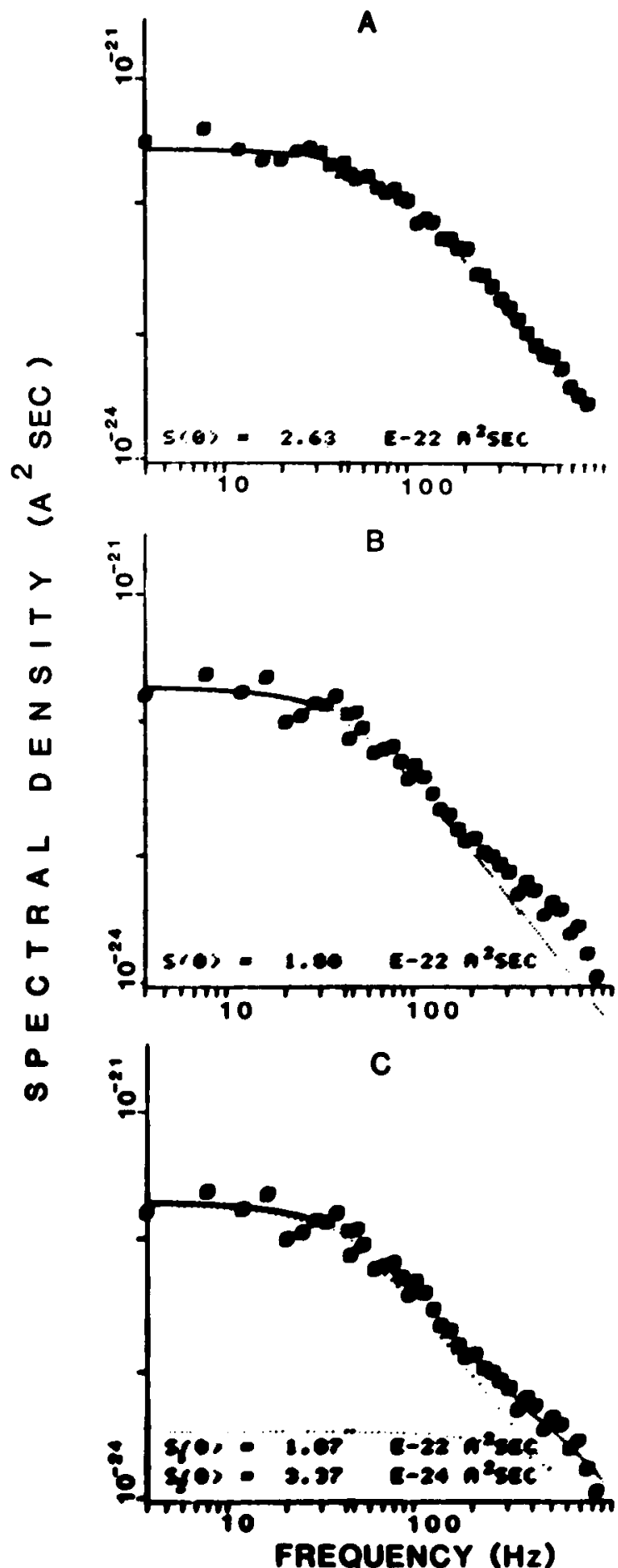

Figure 6 . The presence of two components to the power spectra was more obvious in higher concentrations of neostigmine. Spectral density plots similar to those shown in Figure 5 are shown here from a different fiber exposed to $7.5 \times 10^{-5} \mathrm{M}$ neostigmine. $A$ was obtained in control solution and was fit with an $f_{o}$ of $80 \mathrm{~Hz}$, corresponding to a time constant of 1.98 msec. $B$ represents the best fit to a single Lorentzian with a time constant of $3.18 \mathrm{msec}$. This record illustrates the presence of a high frequency component induced by neostigmine in high concentrations. $C$ is the same record as $B$ fitted with two Lorentzian components; $f_{1}=51 \mathrm{~Hz}$ and $f_{2}=396 \mathrm{~Hz}$. The amplitudes were $1.87 \times 10^{-22}$ $\mathrm{A}^{2}$ sec and $3.75 \times 10^{-24} \mathrm{~A}^{2}$ sec for $f_{1}$ and $f_{2}$, respectively. 


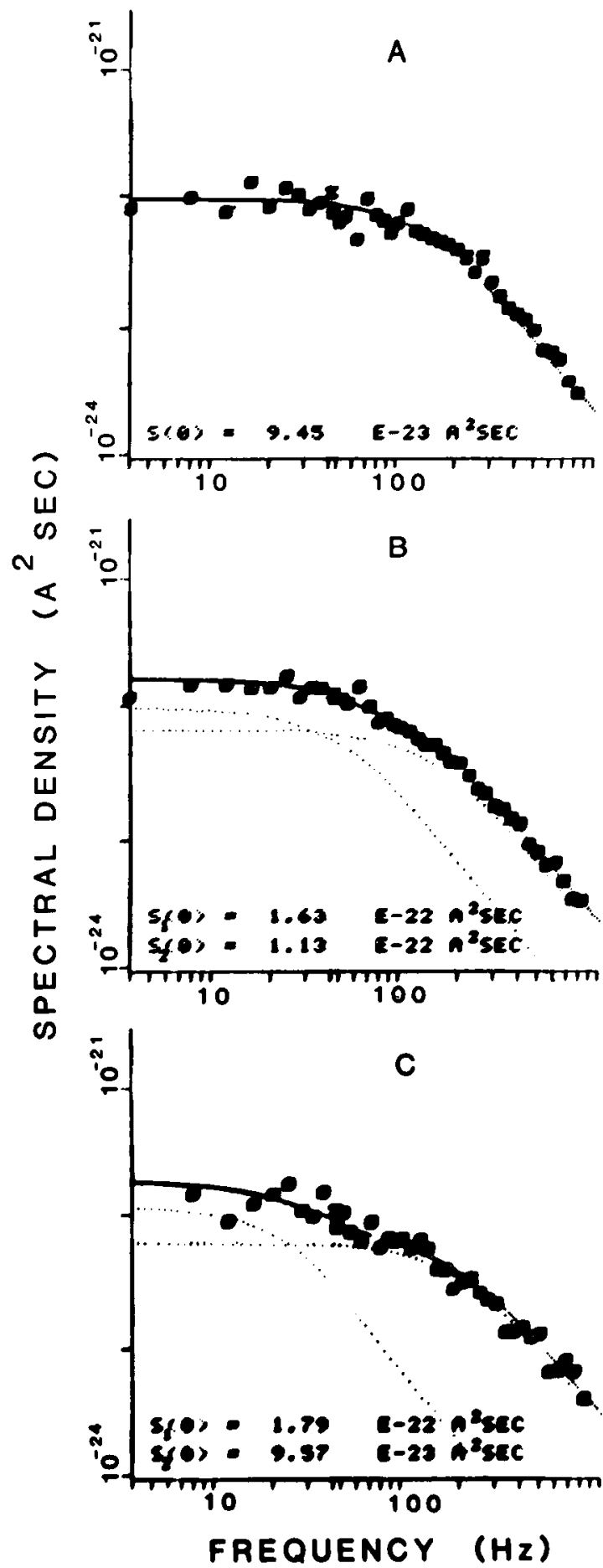

Figure 7. Spectral density plots obtained from $\mathrm{CCh}$-induced current fluctuations in the same fiber voltage clamped to $-80 \mathrm{mV}$ in control solution $(A)$ and sequentially exposed to $5 \times 10^{-5} \mathrm{M}(B)$ and $10^{-4} \mathrm{M}$ (C) neostigmine. In control solution the spectral density plot could be fitted with a single Lorentzian component with a cut-off frequency of $153 \mathrm{~Hz}(\tau=1.04 \mathrm{msec})$ and a zero frequency amplitude of $9.45 \times 10^{-23}$ $\mathrm{A}^{2}$ sec. In $5 \times 10^{-5} \mathrm{M}$ neostigmine $(B)$, two components were required to fit the spectral plots, $f_{1}=58 \mathrm{~Hz}$ and $f_{2}=176 \mathrm{~Hz}$. Increasing the concentration of neostigmine to $10^{-4} \mathrm{M}(C)$ decreased the rate of the slow frequency component and increased the rate of the fast component such that $f_{1}=26 \mathrm{~Hz}$ and $f_{2}=225 \mathrm{~Hz}$. demonstrate a greater depression in peak MEPC amplitude in the higher concentrations of neostigmine at hyperpolarized membrane potentials which resulted in some nonlinearity to the MEPC-voltage relationship. Figure 3 illustrates the relationship between mean peak MEPC amplitude and membrane potential for several concentrations of neostigmine. The reduction in peak MEPC amplitude indicates that neostigmine has additional actions on the $\mathrm{ACh}$ receptor channel complex.

In low concentrations of neostigmine, MEPC decay was well described by a single exponential function, and power spectral density curves were adequately described by a single Lorentzian line shape. However, MEPCs recorded in higher concentrations of neostigmine $\left(>5 \times 10^{-5} \mathrm{M}\right)$ frequently required the sum of two exponential components to fit the decay phase. The decay of MEPCs in the high concentrations of neostigmine reflects a number of simultaneous rate processes, and there was considerable variability from fiber to fiber in the number and the rates of the decay components. The presence of biphasic MEPCs was concentration dependent; as the concentration was increased, a greater percentage of recorded MEPCs required two exponential components, with one component slower and one faster than the control rate of decay. Table II illustrates the results from four fibers exposed to $5 \times 10^{-5} \mathrm{M}$ neostigmine. In each fiber, MEPCs recorded at membrane potentials of $-60 \mathrm{mV}$ and below were well described by a single exponential function.

The voltage dependence of the slow time constant, -0.0144 $\pm 0.0008 / \mathrm{mV}$, when examined in the same fiber was not significantly different from the voltage dependence of the control MEPCs in low concentrations of neostigmine. However, concentrations of neostigmine above $5 \times 10^{-5} \mathrm{M}$ increased this voltage dependence above control values. Although no consistent changes were observed in the value of the fast time constant, the slow time constant increased significantly with membrane hyperpolarization when determined in the same fiber (Table II).

High concentrations of neostigmine alter channel properties. High concentrations of neostigmine $>2.5 \times 10^{-5} \mathrm{M}$ produced power spectral density curves which could no longer be fitted by a single Lorentzian line shape but required the sum of two components. In $2.5 \times 10^{-5} \mathrm{M}$ neostigmine, power density spectra recorded at $-80 \mathrm{mV}$ in 7 of 11 fibers required two time constants. These effects of neostigmine were voltage dependent because power spectra recorded in all of these fibers required two components at $-100 \mathrm{mV}$ and one component at $-60 \mathrm{mV}$. The appearance of a second fast time constant to these curves was consistently present in concentrations of neostigmine $\geq 5$ $\times 10^{-5} \mathrm{M}$ at $-80 \mathrm{mV}$. Figure 4 illustrates MEPCs and noise spectra obtained in the same fiber before and after $2.5 \times 10^{-5}$ $M$ neostigmine. The time constant of MEPC decay was increased from $2.1 \mathrm{msec}$ to $3.8 \mathrm{msec}$, and the spectral curve could only be fit with two time constants. The cut-off frequency for spectral fluctuations in control solution was $76 \mathrm{~Hz}(\tau=2.09$ msec). Following a 20 -min equilibration with $2.5 \times 10^{-5} \mathrm{M}$ neostigmine, the spectral fluctuations demonstrated two components with one component faster $\left(f_{1}=135 \mathrm{~Hz}\right)$ and one slower $\left(f_{2}=46 \mathrm{~Hz}\right)$ than control $(76 \mathrm{~Hz})$. Mean values for the cut-off frequencies in $2.5 \times 10^{-5} \mathrm{M}$ neostigmine were $45.0 \pm 6.0$ Hz. $(n=7)$ and $159 \pm 23 \mathrm{~Hz}(n=7)$ at $-80 \mathrm{mV}$.

Figure 5 illustrates the effects of membrane hyperpolarization on each spectral component in $5 \times 10^{-5} \mathrm{M}$ neostigmine. Spectral fluctuations were obtained with iontophoretic application of $\mathrm{ACh}$ in control solution (Fig. 5A) and in the same fiber exposed to neostigmine at two membrane voltages. The exposure to neostigmine converted the single Lorentzian line shape obtained in the control solution to a spectrum requiring the sum of two Lorentzian components (Fig. $5 B$ ). As observed previously, one component was faster and one slower than the 

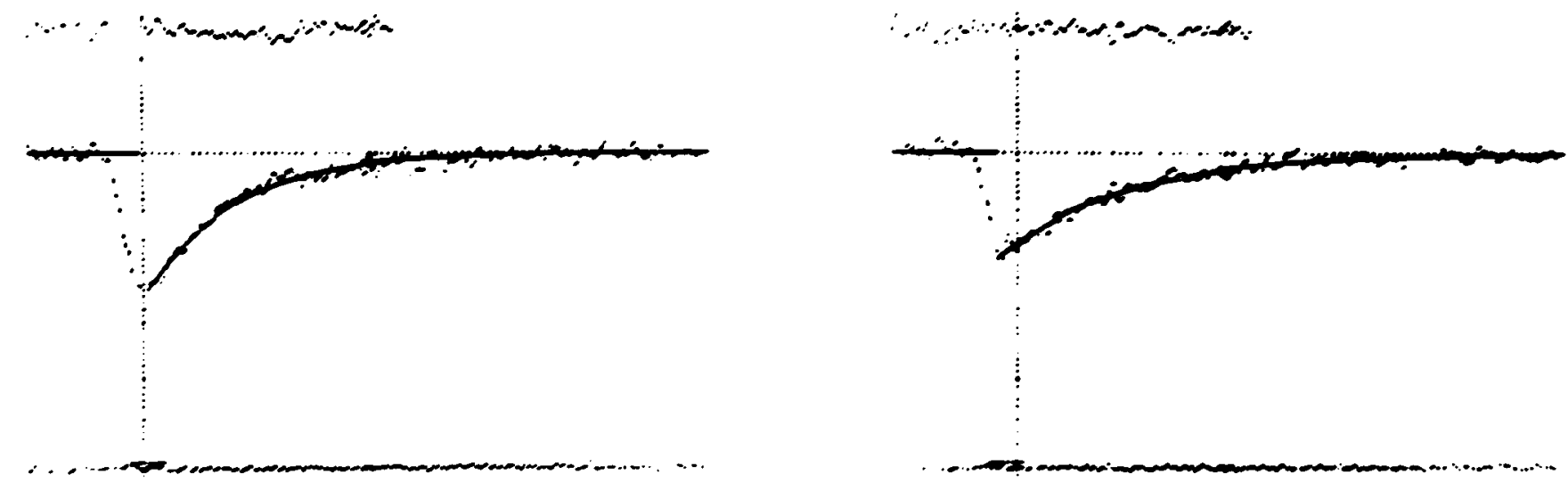

Figure 8 . The effect of pretreatment with collagenase on the time course of MEPCs. $A$ represents a mean MEPC of 20 individual MFPCs recorded at $-80 \mathrm{mV}\left(20^{\circ} \mathrm{C}\right)$ following collagenase $(0.2 \%$ for $120 \mathrm{~min})$. The decay time constant was prolonged with respect to control $\mathrm{MEPCs}$ and the amplitude was decreased following collagenase. $B$ is a mean MEPC recorded in the same fiber following exposure to $10^{-4} \mathrm{M}$ neostigmine. The peak MEPC amplitude was decreased to $-0.79 \mathrm{nA}$ and the decay rate further decreased to $0.207 \mathrm{msec}(\tau=5.0 \mathrm{msec})$.

single control rate component. Hyperpolarizing the same fiber to $-123 \mathrm{mV}$ (Fig. $5 \mathrm{C}$ ) altered the cut-off frequencies of each spectral component such that the fast component was increased and the slow component decreased. Higher concentrations of neostigmine better illustrate the contribution of the fast component to the power density spectra. Figure 6 demonstrates the results obtained in a separate fiber exposed to $7.5 \times 10^{-5} \mathrm{M}$ neostigmine. Three spectral density plots obtained at the same membrane voltage $(-82 \mathrm{mV})$ are shown. Figure $6 A$ represents the control. Figure $6, B$ and $C$, represents the same spectrum fit with one (Fig. 6A) and two (Fig. 6B) time constants. Figure $6 B$ illustrates the poor fit with a single time constant and demonstrates the presence of the high frequency component produced by neostigmine. Mean values for the cut-off frequencies were $43.5 \pm 8.0 \mathrm{~Hz}(n=7)$ and $422 \pm 5 \mathrm{~Hz}(n=7)$ in $5 \times$ $10^{-5} \mathrm{M}$ neostigmine and $36.8 \pm 6.8 \mathrm{~Hz}(n=6)$ and $411 \pm 50 \mathrm{~Hz}$ $(n=6)$ in $10^{-4} \mathrm{M}$ neostigmine. The slow time constant increased, however, with membrane hyperpolarization and with increasing concentrations of neostigmine when examined in the same fiber. The fast time constant decreased with increasing concentrations of neostigmine up to $7.5 \times 10^{-5} \mathrm{M}$ with no further decrease observed at higher concentrations. It appears as though the rate of the fast component became saturated at high concentration such that further increases in the concentration of neostigmine had little to no effect. However, the amplitude of the fast component increased with either membrane hyperpolarization or increases in the concentration of neostigmine.

Similar results are obtained with $C C h$. The previous results demonstrate that high concentrations of neostigmine produce biphasic MEPC decays and power spectra which require the sum of two time constants. One of the possible explanations for this observation is that the results are not the direct effect of neostigmine but rather reflect the consequence of $\mathrm{ACh}$ accumulation within the synaptic cleft. The shapes of the power density spectral curves resemble those obtained in the presence of channel-blocking drugs, and it is possible that ACh in high concentrations could block the open state of the ACh receptor channel complex (Sine and Steinbach, 1984). A simple test to eliminate this possibility is to repeat the experiments using $\mathrm{CCh}$ to activate the $\mathrm{ACh}$ receptor channel complex. $\mathrm{CCh}$ is a nonhydrolyzable agonist which would not accumulate within the synaptic cleft as a consequence of esterase inhibition. Figure
$7 \mathrm{~A}$ demonstrates that $\mathrm{CCh}$ in the absence of neostigmine produces power spectral density curves which are well described by a single Lorentzian line shape. As reported previously, the mean lifetime of the $\mathrm{ACh}$ channel is much briefer when activated by CCh (Neher and Sakmann, 1977). The mean cut-off frequency in control solution was $147 \pm 10.0 \mathrm{~Hz}(n=8)$, yielding a mean channel lifetime of $1.06 \pm 0.07 \mathrm{msec}$. Concentrations of neostigmine up to and including $10^{-5} \mathrm{M}$ did not alter the spectral shape or the cut-off frequency of $\mathrm{CCh}$-induced spectral curves. Figure $7, B$ and $C$, illustrates power spectral density curves obtained using carbachol in the same fiber exposed sequentially to $5 \times 10^{-5}$ (Fig. $7 B$ ) and $10^{4} \mathrm{M}$ (Fig. 7C) neostigmine. These higher concentrations of neostigmine produced spectral density curves which required the sum of two time constants. Increasing the concentration of neostigmine in the same fiber (at a constant membrane potential, $-80 \mathrm{mV}$ ) increased the time constant of the slow component from 2.6 to $6.6 \mathrm{msec}$ and decreased the time constant of the fast component from 0.9 to $0.8 \mathrm{msec}$. In eight separate experiments with $\mathrm{CCh}$, the effects of membrane hyperpolarization and increasing concentrations of neostigmine had qualitatively the same effects as observed previously with iontophoretic application of $\mathrm{ACh}$. One significant and consistent difference which was observed between the two agonists was that the cut-off frequency for the fast time constant in high concentrations of neostigmine was significantly higher for iontophoretic application of $\mathrm{ACh}$ than with CCh. For example, the cut-off frequency for the fast component in $10^{-4} \mathrm{M}$ neostigmine was $411 \pm 62 \mathrm{~Hz}(n=7)$ for $\mathrm{ACh}$ and $199 \pm 40 \mathrm{~Hz}(n=5)$ for $\mathrm{CCh}$.

Multiple component spectra are also obtained after collagenase treatment. In a separate series of experiments, the muscle was pretreated with collagenase for $2 \mathrm{hr}$ before any recordings were made. This procedure results in the removal of esterase from the synaptic cleft (Betz and Sakmann, 1971, 1973; Hall and Kelly, 1971) and consequently prolongs the duration of $\mathrm{ACh}$ in the synaptic cleft (Magleby and Terrar, 1975). The rate of decay of MEPCs recorded from a muscle treated for 2 hr with collagenase were considerably slower than MEPCs recorded from control muscles (Fig. $8 A$ ). The mean time constant for the decay of MEPCs recorded at $-80 \mathrm{mV}$ was increased from $2.09 \pm 0.57 \mathrm{msec}(n=32)$ to $3.25 \pm 0.52 \mathrm{msec}(n=10)$ following collagenase treatment. This represents a 1.6 -fold increase in the MEPC decay time constant, a value similar to that reported 

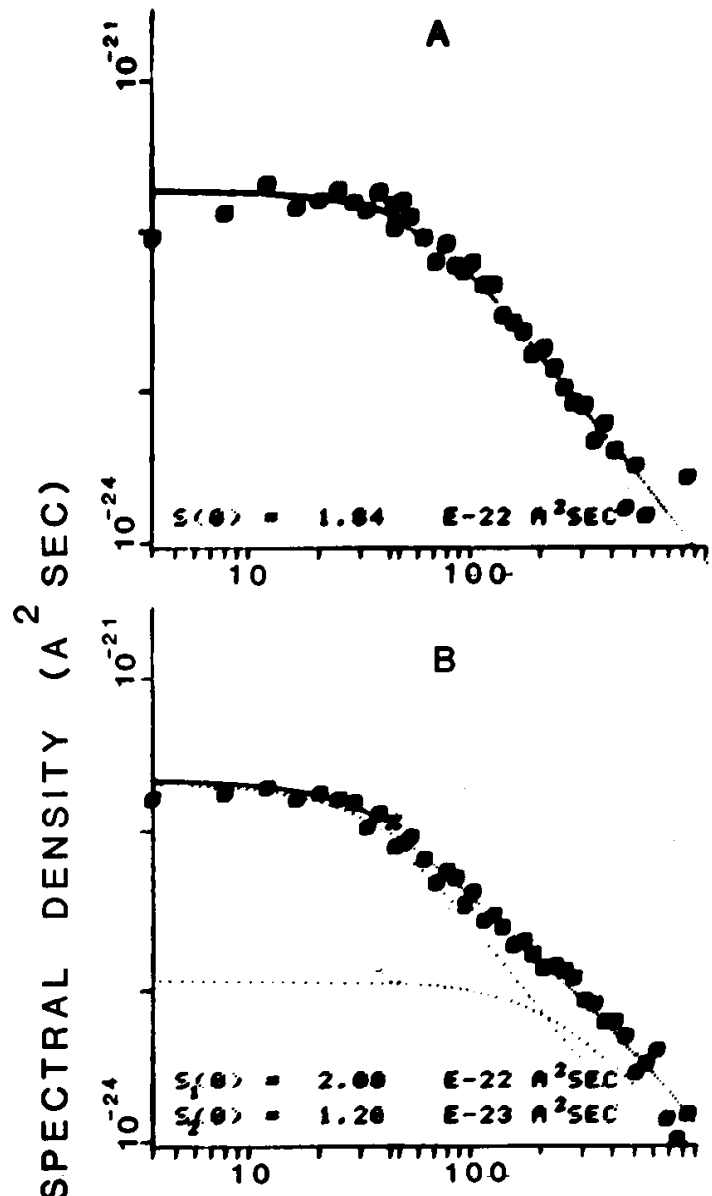

$\infty$

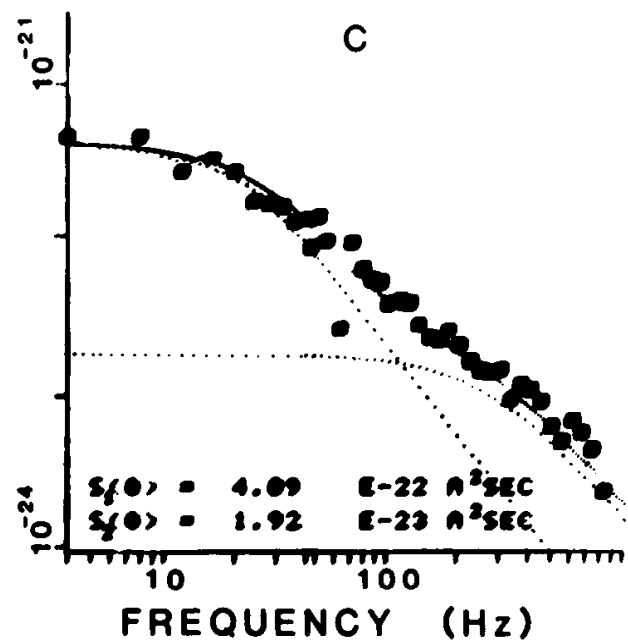

Figure 9. Pretreatment with collagenase did not alter the basic properties of ACh receptor channel gating. $A$ shows spectral density plots recorded in a fiber following collagenase treatment. The plot is well fit by a single Lorentzian with a cut-off frequency of $63 \mathrm{~Hz}(\tau=$ $2.52 \mathrm{msec}$ ) and a zero frequency amplitude of $1.84 \times 10^{-22} \mathrm{~A}^{2}$ sec. $B$ and $C$ represent spectral plots obtained in the same fiber exposed to $10^{-4} \mathrm{M}$ neostigmine at $-80 \mathrm{mV}(B)$ and $-100 \mathrm{mV}(C)$. In $B, f_{1}=41 \mathrm{~Hz}$ and $f_{2}=261 \mathrm{~Hz}$. In $C, f_{1}=25 \mathrm{~Hz}$ and $f_{2}=317 \mathrm{~Hz}$. The dotted lines represent the respective amplitudes and rates for each spectral component.

previously for EPCs (Magleby and Terrar, 1975). These results were taken as evidence for partial removal of esterase from the synaptic cleft. Further evidence for partial removal of $\mathrm{AChE}$ from the synaptic cleft following collagenase treatment was obtained by histochemical staining of fibers before and after

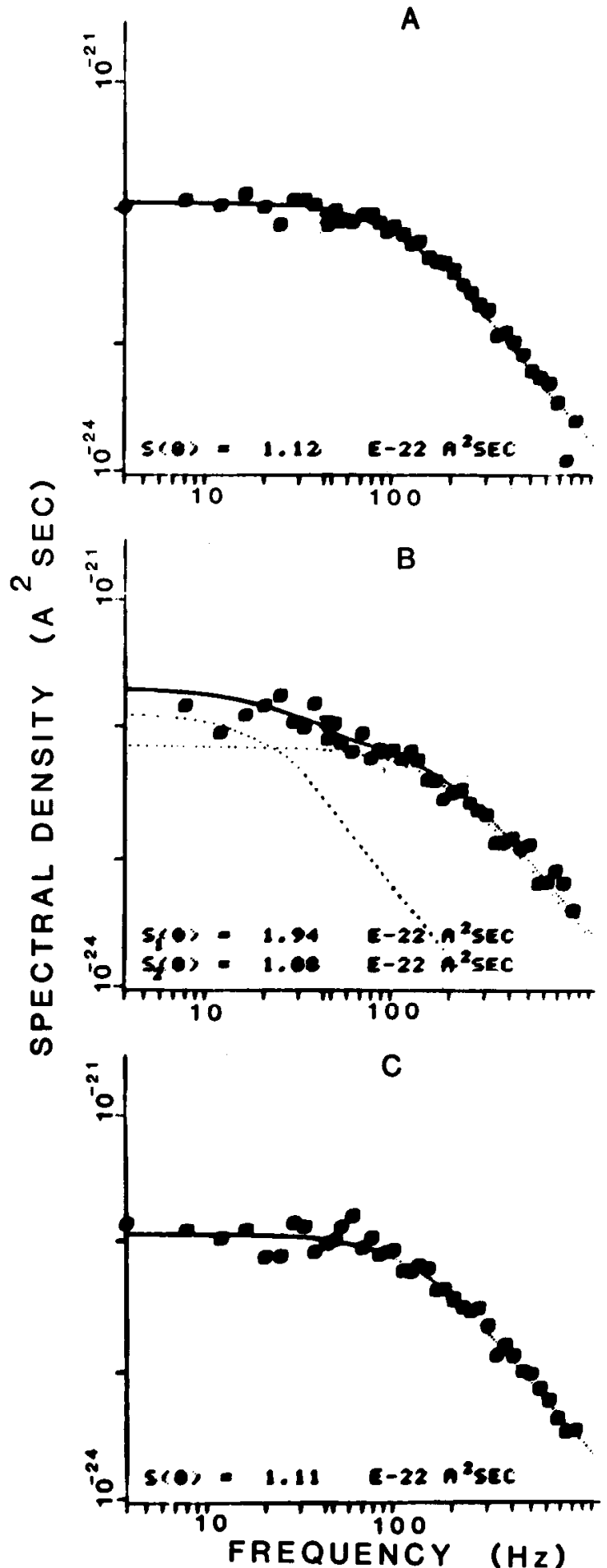

Figure 10. Spectral density plots recorded following collagenase pretreatment in the same fiber at $-80 \mathrm{mV}$. $A$ was recorded in control solution with a single time constant, with a cut-off frequency of 121 $\mathrm{Hz}(\tau=1.31 \mathrm{msec})$ and a zero frequency amplitude of $\left.1.12 \times 10^{-22}\right) \mathrm{A}^{2}$ sec. $B$ was recorded from the same fiber in $10^{-4} \mathrm{M}$ neostigmine. Two component spectra were obtained. In this fiber, $f_{1}=24 \mathrm{~Hz}$ and $f_{2}=199$ $\mathrm{Hz}$ with respective amplitudes of $1.94 \times 10^{-22}$ and $1.08 \times 10^{-22} \mathrm{~A}^{2}$ sec. $C$ was obtained in the same fiber following a return to control solution and illustrates the reversibility of the effect(s) of neostigmine by reverting the multiple component spectra to a single component. For $C, f_{o}=129 \mathrm{~Hz}(\tau=1.13 \mathrm{msec})$ and the zero frequency amplitude was $1.38 \times 10^{-22} \mathrm{~A}^{2} \mathrm{sec}$. 

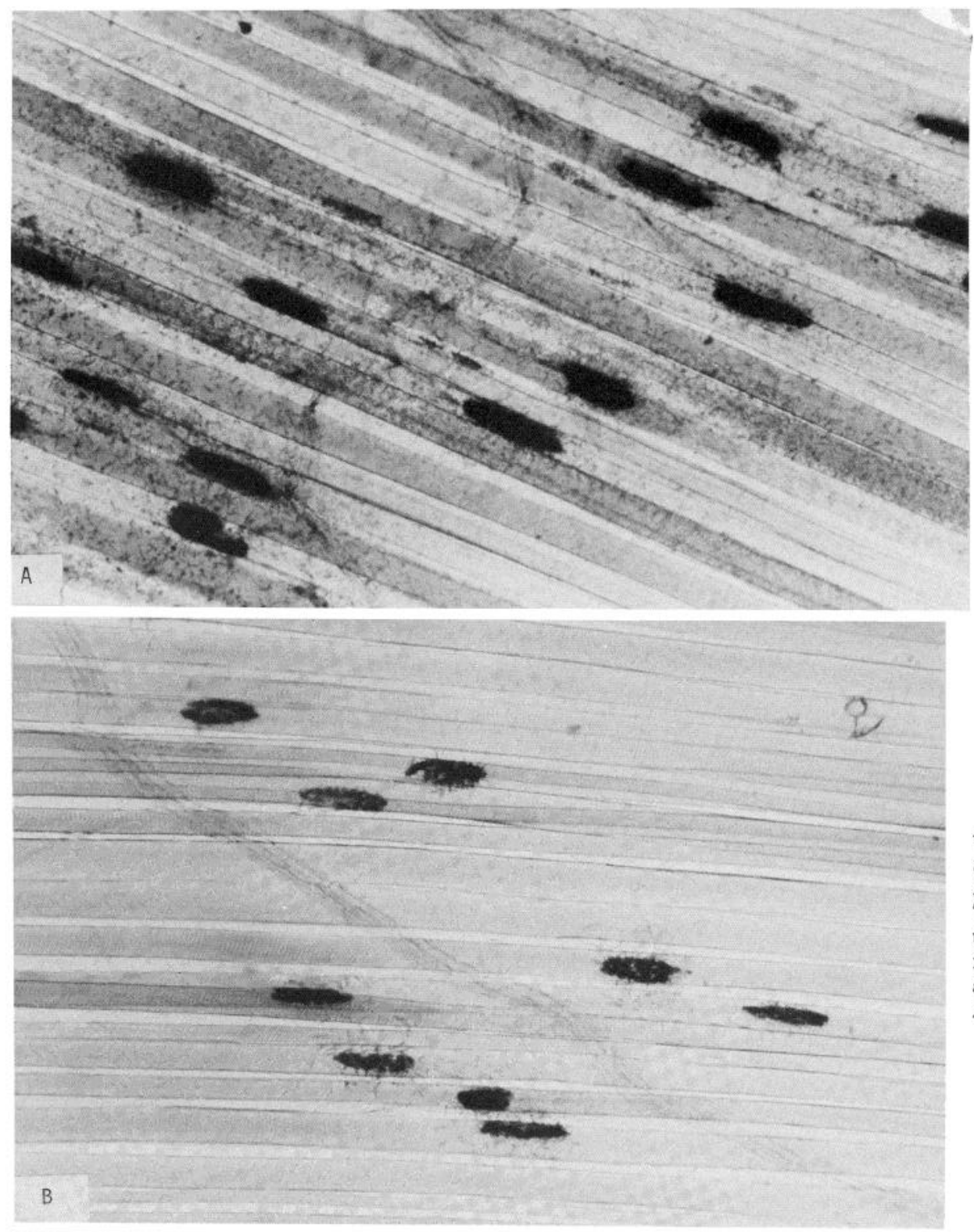

Figure 11. Photomicrographs of costocutaneous muscles of the garter snake (Thamnophis) showing histochemical localization of $\mathrm{AChE}$ on motor endplates of twitch fibers. The substrate was acetylthiocholine. $A$, Control; $B$, collagenase treatment $(2 \mathrm{hr}, 2 \mathrm{mg} /$ $\mathrm{ml}) ; C, 10^{-4} \mathrm{M}$ neostigmine following collagenase, demonstrating complete inhibition of $\mathrm{AChE}$ activity. Magnification $\times 100$.

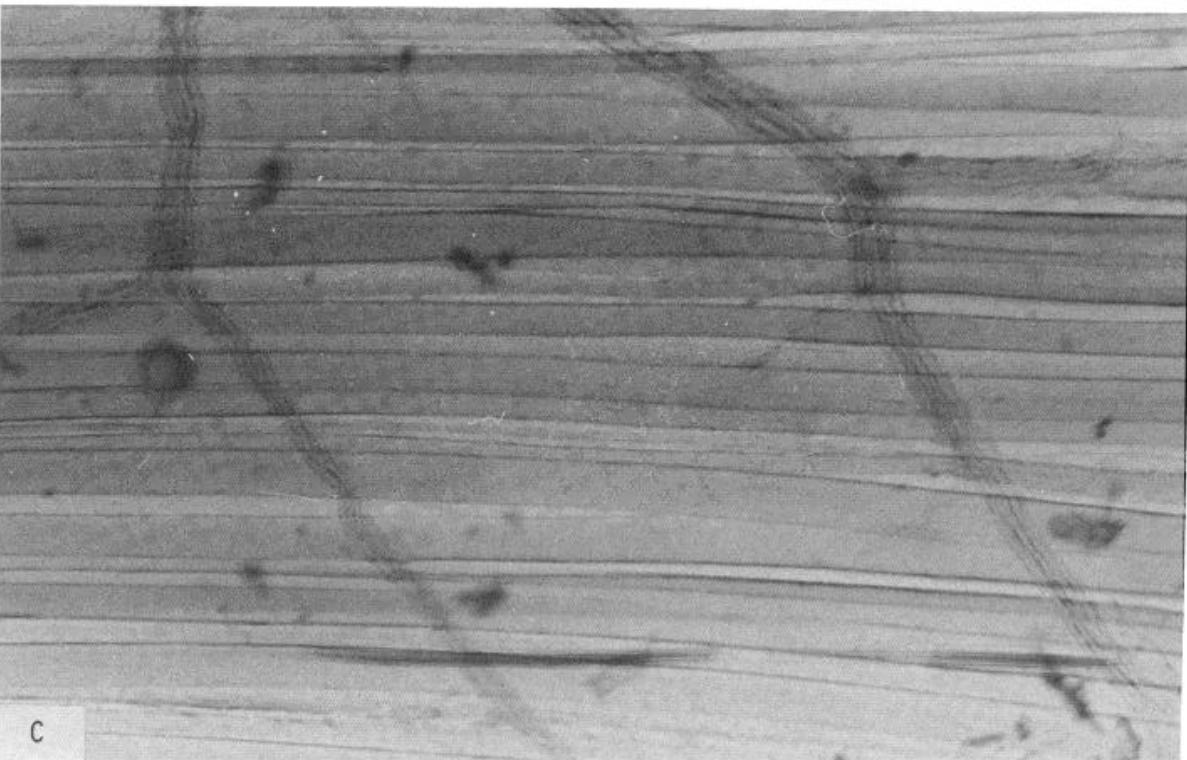


collagenase treatment (see Fig. 11). The peak MEPC amplitude was generally reduced in collagenase-treated fibers, presumably due to a partial separation of the presynaptic nerve terminal from the postjunctional membrane.

Exposure of the enzyme-treated fibers to neostigmine further increased the time constant of MEPC decay (Fig. 8B) and further decreased histochemical staining for $\mathrm{AChE}$ in twitch fiber endplates (see Fig. $11 \mathrm{C}$ ). Although the rate of rise, peak current amplitude, and time constant of MEPC decay were altered by collagenase treatment, there was no significant effect of this enzyme pretreatment on the characteristic frequency or the conductance of the $\mathrm{ACh}$ receptor channel complexes activated by either $\mathrm{ACh}$ or $\mathrm{CCh}$ when compared to untreated controls (see Figs. $9 A$ and 10A; Kuba et al., 1974; Katz and Miledi, 1975). In addition, concentrations of neostigmine up to and including $10^{-5} \mathrm{M}$ did not alter these parameters. Higher concentrations of neostigmine, however, produced power spectral density curves which required the sum of two time constants to fit properly. These spectral fluctuations were best described by a low and a high frequency component with time constants and amplitudes comparable to those obtained in untreated muscles exposed to the same concentrations of neostigmine. Figure 9 illustrates power spectral density curves obtained from ACh-induced current fluctuations in a single fiber following collagenase treatment. In this fiber, neostigmine $\left(10^{-4} \mathrm{M}\right)$ converted the control spectrum with a single cut-off frequency of $63 \mathrm{~Hz}$ to a two-component spectrum with cut-off frequencies of 41 and $261 \mathrm{~Hz}$. Hyperpolarizing this fiber decreased the frequency of the slow component to $25 \mathrm{~Hz}$ and increased the rate of the fast component $(317 \mathrm{~Hz})$. Figure 10 demonstrates the result of a similar experiment in which $\mathrm{CCh}$ was iontophoretically applied. Power spectra were obtained from the same fiber voltage clamped to $-80 \mathrm{mV}$ and sequentially exposed to control solution (Fig. $10 \mathrm{~A}$ ), neostigmine, $10^{-4}$ M (Fig. 10B), and a return to control solution (wash, Fig. 10C). In the presence of neostigmine, two component spectra were obtained. Following a return to control solution and washing for $20 \mathrm{~min}$, the spectrum of current fluctuations returned to control values, demonstrating the reversibility of the effects of neostigmine on the $\mathrm{ACh}$ receptor channel complex.

\section{Discussion}

Under normal conditions, activation of $\mathrm{ACh}$ receptors at the neuromuscular junction can be described by the following kinetic schema.

$$
\begin{aligned}
& \text { Products } \\
& \mathrm{AChE} \uparrow \mathrm{k}_{2} \\
& \mathrm{ACh} \rightleftharpoons(\mathrm{ACh})_{2}+\mathrm{R} \underset{k_{-1}}{\stackrel{k_{1}}{\rightleftarrows}}(\mathrm{ACh})_{2} \mathrm{R} \underset{\alpha}{\stackrel{\beta}{\rightleftarrows}}(\mathrm{ACh})_{2} \mathrm{R}^{*} \\
& \downarrow k_{3}
\end{aligned}
$$

Two molecules of agonist bind to the postjunctional ACh receptor to form an intermediate, nonconducting complex $\left(\mathrm{ACh}_{2} \mathrm{R}\right)$ which may convert to the open conductance state $\left(\mathrm{ACh}_{2} \mathrm{R}^{*}\right)$. The rates governing agonist association with receptors and the removal of $\mathrm{ACh}$ from the synaptic cleft, via diffusion and hydrolysis, are high and it is assumed that the rate constant for the closing of the $\mathrm{ACh}$ receptor channel complex determines the time course of the postjunctional conductance change.

The decay of synaptic currents recorded following AChE inhibition is dependent on a number of simultaneous reactions. In addition to the normal rate-limiting step, believed to be a conformation change in a gating molecule associated with the receptor, other processes which might affect the decay are: (1) multiple binding of $\mathrm{ACh}$ to receptors due to the high cleft concentration of $\mathrm{ACh},(2)$ delayed diffusion from the synaptic cleft, (3) a direct effect of neostigmine on the ACh receptor channel complex, and (4) variability in the geometry of the synaptic cleft region and the density of $\mathrm{ACh}$ receptors from fiber to fiber. The present results demonstrate that low concentrations of neostigmine inhibit the hydrolysis of ACh, resulting in an increase in the MEPC decay time constant and an increase in MEPC amplitude without altering the lifetime or conductance of individual $\mathrm{ACh}$ receptor channel complexes. These results are consistent with the interpretation that, in the presence of neostigmine, current decay is determined by delayed diffusion as a result of repetitive binding of $\mathrm{ACh}$ to available receptors as $\mathrm{ACh}$ diffuses out of the synaptic cleft (Katz and Miledi, 1973; Magleby and Terrar, 1975). However, analysis of synaptic current decay in the present paper and by others (Magleby and Stevens, 1972a, b; Gage and McBurney, 1975) demonstrates that, in the presence of neostigmine, current decay, although prolonged, is well described by a single exponential function. In addition, the dependence of MEPC decay on the value of the membrane potential is unaltered by neostigmine. Several possibilities could account for these ex perimental observations. One is that the process of diffusion in the presence of neostigmine exhibits a voltage dependence similar to that in untreated controls. The origin of this voltage dependence is unknown but could reside in the binding reactions of ACh with the receptor (Colquhoun, 1975). Alternatively, the observed voltage dependence may represent a combination of several rate processes, the magnitudes of which cannot be resolved independently in the decay of the synaptic currents. As a result of these apparent discrepancies, a direct effect of neostigmine on the receptor channel complex to prolong the mean lifetime of endplate channels has been suggested (Magleby and Stevens, 1972b). Direct effects of neostigmine were not observed in the present study in concentrations below and including $10^{-5} \mathrm{M}$. Further experiments on the nature of the voltage dependence in low concentrations of anticholinesterase agents are required to resolve this issue.

When concentrations of neostigmine above $2.5 \times 10^{-5} \mathrm{M}$ were used (see also Magleby and Stevens, 1972a, b; Gage and Mc. Burney, 1975), direct actions of neostigmine were observed: MEPC decay was converted into two components, MEPC amplitude was reduced, and current fluctuation spectra required the sum of two Lorentzian components. Although biphasic MEPC have been observed with high concentrations of di-isopropylfluorophosphate (DFP) (Kuba et al., 1974), edrophonium (Goldner and Narahashi, 1974), eserine (Kordas et al., 1975), and prostigmine (neostigmine) (Kordas, 1977), these results were not analyzed over either a range of concentrations or of membrane potentials, and EPC fluctuations were not recorded.

Evidence for a direct action of neostigmine on the ACh receptor channel complex is supported in this paper by the fact that similar results were obtained using different experimental approaches. If the two-component spectra were due to an accumulation of $\mathrm{ACh}$ within the synaptic cleft following neostigmine, then similar results would not be expected using $\mathrm{CCh}$ induced current fluctuations. Since $\mathrm{CCh}$ is a nonhydrolyzable agonist, the concentration would not increase due to $\mathrm{AChE}$ inhibition. The current fluctuation spectra obtained using $\mathrm{CCh}$ were qualitatively identical to those obtained using $\mathrm{ACh}$ as the agonist. Biphasic MEPC decays and two-component spectra were also obtained following collagenase treatment. Collagenase pretreatment has been shown to remove $\mathrm{AChE}$ from amphibian endplate regions, and similar results were obtained in the present experiments using snake muscles (Fig. 11). Al- 
though some histochemical staining for AChE remained following this treatment, the staining was much reduced and became less in the presence of neostigmine (Fig. 11). These data indicate that the high frequency component in the spectra was a result of a direct action of neostigmine and not the result of enzyme inhibition.

$$
2 \mathrm{ACh}+\mathrm{R} \underset{k_{-1}}{\stackrel{k_{1}}{\longleftrightarrow}}(\mathrm{ACh})_{2} \mathrm{R} \underset{\alpha}{\stackrel{\beta}{\longleftrightarrow}}(\mathrm{ACh})_{2} \mathrm{R}^{*}
$$

The simplified kinetic schema depicted above predicts that, with two kinetically distinct states, data should be described by a single time constant since the number of basic components is one less than the number of kinetic states (Colquhoun and Hawkes, 1977). Here it is assumed that the rate of association of $\mathrm{ACh}$ with receptors is high with respect to channel gating and that the closed states of the receptor are indistinguishable. It is clear that synaptic responses obtained in the presence of neostigmine were more complex than a single component and require a kinetic model with at least three states. With three distinct states, MEPCs would be fit with the sum of two exponential components having different time constants, and current fluctuation spectra would require the sum of two Lorentzian components with different corner frequencies, as observed experimentally. A three-state model has been described for numerous drugs which produce an open channel block (Adams, 1976; Ruff, 1977). One analysis of the open channel blocking mechanism is accomplished by comparing the rates and amplitudes of MEPCs with the rates and amplitudes of the respective spectral components. This is based on the assumption that a direct effect on channel kinetics predicts that the lifetime calculated from the noise spectra should be prolonged by the same amount as the MEPC decay. In the present experiments, however, considerable variability in the decay of MEPCs was observed, and the decay components were not similar to the spectral components. When examined in the same fiber, the time constant for the fast component of MEPC decay did not decrease with voltage and concentration of neostigmine as expected for an open channel blocker (see Table II). Rather, the time constants for both the fast and slow decay components increased with either membrane hyperpolarization or increasing concentrations of neostigmine. The amplitude of the fast component did increase, however, with membrane hyperpolarization and increasing concentrations of neostigmine.

The reciprocal of the rate of EPC decay in control solution is similar to the mean lifetime of the open state of the $\mathrm{ACh}$ receptor channel complex determined from noise analysis (Magleby and Stevens, 1972a, b; Anderson and Stevens, 1973). Recent single-channel recordings using high resolution methods suggest that the mean channel lifetime is actually the mean lifetime of a single-channel burst. Rather than a square pulse of current, a single-channel current appears as a burst of current with pulses in very quick succession (Colquhoun and Hawkes, 1977; Trautman and Siegelbaum, 1983). These "flickers" within the channel-opening event would be expected to give rise to components of very low amplitude in noise spectra so that, even when the component is within the observable frequency range, it could easily be missed.

Trautman (1983) has proposed that the differences between agonists may be due to differences in the rate of dissociation of agonists from the receptor and that the differences are reflected in both the potencies and the number of oscillations of a channel between the open and closed states within a burst. In the present context, neostigmine may have a direct stabilizing effect on the receptor channel complex to prolong agonist occupancy on the receptor and therefore decrease the rate of agonist dissociation. This drug induced complex could result in single-channel openings with numerous quick flickers within the burst which would produce a high frequency component to current fluctuation spectra whose amplitude increases with neostigmine concentration as observed experimentally. In the present experiments, the amplitude of the fast frequency component increased with both $\mathrm{ACh}$ and $\mathrm{CCh}$, but the cut-off frequency was much higher for $\mathrm{ACh}$ than for $\mathrm{CCh}$. According to this theory, the stabilized complex would result in an increase in the oscillation between open $\left(\mathrm{ACh}_{2} \mathrm{R}^{*}\right)$ and closed $\left(\mathrm{ACh}_{2} \mathrm{R}\right)$ states of the receptor (see also Dionne, 1981). The development of a neostigmine-induced stabilization of the closed state of the receptor is a possibility and is consistent with the data which demonstrate two spectral components. In low concentrations of neostigmine, the high frequency component, although possibly present, would not be resolvable due to its low amplitude, and the spectral fluctuations would be described by a single time constant similar to that of control.

The slow frequency component was slower than the control and became slower with increasing concentrations of neostigmine. This component could represent a burst duration and could reflect the prolonged lifetime of agonist association. Distinguishing between several complex models for channel behavior or the resolving of heterogeneities in the channel population in the presence of neostigmine can best be resolved using single-channel analysis. It is apparent, however, that the actions of neostigmine are complex and concentration dependent.

\section{References}

Adams, P. R. (1976) Drug blockade of open end-plate channels. J. Physiol. (Lond.) 260: 531-552.

Adams, P. R. (1981) Acetylcholine receptor kinetics. J. Membr. Biol 58: $161-174$

Akaike, A., S. R. Ikeda, N. Brookes, G. J. Pascuzzo, D. L. Rickett, and E. X. Albuquerque (1984) The nature of the interactions of pyridostigmine with the nicotinic acetylcholine receptor-ionic channel complex. II. Patch clamp studies. Mol. Pharmacol. 25: 102-112.

Alderdice, M. T. (1982) Further comparison of the effects of physostigmine and neostigmine on frog neuromuscular transmission. Clin Exp. Pharmacol. Physiol. 9: 35-43.

Anderson, C. R., and C. F. Stevens (1973) Voltage clamp analysis of acetylcholine produced end-plate current fluctuations at frog neuromuscular junction. J. Physiol. (Lond.) 235: 655-691.

Betz, W., and B. Sakmann (1971) Dysjunction of frog neuromuscular synapses by treatment with proteolytic enzymes. Nature New Biol. 232: 94-95.

Betz, W., and B. Sakmann (1973) Effects of proteolytic enzymes on function and structure of frog neuromuscular junction. J. Physiol. (Lond.) 230: 673-688.

Colquhoun, D. (1975) Mechanisms of drug action at the voluntary muscle endplate. Annu. Rev. Pharmacol. 15: 307-325.

Colquhoun, D., and A. G. Hawkes (1977) Relaxation and fluctuations of membrane currents that flow through drug-operated ion channels. Proc. R. Soc. Lond. (Biol.) 199: 231-262.

Connor, E. A., S. L. Levy, and R. L. Parsons (1983) Kinetic analysis of atropine-induced alterations in bullfrog ganglionic fast synaptic currents. J. Physiol. (Lond.) 225: 496-502.

Dionne, V. E. (1976) Characterization of drug iontophoresis with a fast microssay technique. Biophys. J. 16: 705-717.

Dionne, V.E. (1981) The kinetics of slow muscle acetylcholine-operated channels in the garter snake. J. Physiol. (Lond.) 310. 159-190.

Dionne, V. E., and R. L. Parsons (1981) Characteristics of the acetylcholine-operated channel at twitch and slow fiber neuromuscular junctions of the garter snake. J. Physiol. (Lond.) 310: 145-158.

Dionne, V. E., and C. F. Stevens (1975) Voltage dependence of agonist effectiveness at the frog neuromuscular junction: Resolution of a paradox. J. Physiol. (Lond.) 251: 245-270.

Duncan, C. J., and S. J. Publicover (1979) Inhibitory effects of cholin ergic agents on the release of transmitter at the frog neuromuscular junction. J. Physiol. (Lond) 294: 91-103.

Eccles, J. C., and W. V. MacFarlane (1949) Actions of anti-cholinesterases on end-plate potential of frog muscle. J. Neurophysiol. 12 $59-80$. 
Eccles, J. C., B. Katz and S. W. Kuffler (1942) Effect of eserine on neuromuscular transmission. J. Neurophysiol. 5: 211-230.

Fiekers, J. F. (1983a) Direct effects of neostigmine on the end-plate receptor channel complex. Soc. Neurosci. Abstr. 9: 735.

Fiekers, J. F. (1983b) Effects of aminoglycoside antibiotics, streptomycin and neomycin on neuromuscular transmission. II. Postsynaptic considerations. J. Pharmacol. Exp. Ther. 225: 496-502.

Fatt, P., and B. Katz (1951) An analysis of the end-plate potential recorded with an intracellular electrode. J. Physiol. (Lond.) 115: 320 370.

Feng, T. P. (1940) Studies on the neuromuscular junction. XVIII. The local potentials around neuromuscular junctions induced by single and multiple volleys. Chinese J. Physiol. 15: 367-404.

Gage, P. W., and R. N. McBurney (1975) Effects of membrane potential temperature and neostigmine on the conductance change caused by a quantum of acetylcholine at the toad neuromuscular junction. J. Physiol. (Lond.) 244: 385-407.

Goldner, M. M., and T. Narahashi (1974) Effects of edrophonium on end-plate currents in frog skeletal muscle. Eur. J. Pharmacol. 25: $362-371$.

Hall, Z. W., and R. B. Kelly (1971) Enzymatic detachment of endplate acetylcholinesterase from muscle. Nature New Biol. 232: 62-63.

Hess, A. (1965) The sarcoplasmic reticulum, the T system, and the motor terminals of slow and twitch muscle fibers in the garter snake. J. Cell Biol. 26: 467-476.

Katz, B., and R. Miledi (1973) The binding of acetylcholine to receptors and its removal from the synaptic cleft. J. Physiol. (Lond.) 231: 549557.

Katz, B., and R. Miledi (1975) The nature of the prolonged end-plate depolarization in anti-esterase treated muscle. Proc. R. Soc. Lond. (Biol.) 192: 27-38.

Koelle, G., and J. S. Friedenwald (1949) A histochemical method for localizing cholinesterase activity. Proc. Soc. Exp. Biol. Med. 70: 617622.

Kordas, M. (1968) A study of the end-plate potential in sodium deficient solution. J. Physiol. (Lond.) 198: 81-90.

Kordas, M. (1972a) An attempt at an analysis of the factors determining the tme course of the end-plate current. I. The effects of prostigmine and of the ratio of $\mathrm{Mg}^{+2}$ to $\mathrm{Ca}^{+2}$. J. Physiol. (Lond.) 224: 317332.

Kordas, M. (1972b) An attempt at an analysis of the factors determining the time course of the end-plate current. II. Temperature. J. Physiol. (Lond.) 224: 333-348.

Kordas, M. (1977) On the role of junctional cholinesterase in determining the time course of the end-plate current. J. Physiol. (Lond.) 270: 133-150.

Kordas, M., M. Brzin, and Z. Majcen (1975) A comparison of the effect of cholinesterase inhibitors on end-plate current and on cholinesterase activity in frog muscle. Neuropharmacology 14: 791-800.

Kuba, K., and T. Tomita (1971) The effect of prostigmine on the time course of the end-plate potential in the rat diaphragm. J. Physiol. (Lond.) 213: 533-544.

Kuba, K., E. X. Albuquerque, J. Daly, and E. A. Barnard (1974) A study of the irreversible cholinesterase inhibitor, diisopropylfluorophosphate, on time course of end-plate currents in frog sartorius muscle. J. Pharmacol. Exp. Ther. 189: 499-512.

Kuffler, S. W., and D. Yoshikami (1975) The distribution of acetylcholine sensitivity at the post-synaptic membrane of vertebrate skeletal twitch muscles: Iontophoretic mapping in the micron range. J. Physiol. (Lond.) 244: 703-730.

Magleby, K. L., and C. F. Stevens (1972a) The effect of voltage on the time course of end-plate currents. J. Physiol. (Lond.) 223: 151-171.

Magleby, K. L., and C. F. Stevens (1972b) A quantitative description of end-plate currents. J. Physiol. (Lond.) 223: 173-197.

Magleby, K. L., and D. A. Terrar (1975) Factors affecting the time course of current decay of end-plate currents: A possible cooperative action of acetylcholine on receptors of the frog neuromuscular junction. J. Physiol. (Lond.) 244: 467-495.

Miyamolo, M. D. (1978) The action of cholinergic drugs on motor nerve terminals. Pharmacol. Rev. 29: 221-247.

Neher, E., and B. Sakmann (1977) Single channel currents recorded from membranes of denervated frog muscle fibers. Nature 260: 779802.

Pascuzzo, G. J., A. Akaike, M. A. Maleque, K. Shaw, R. S. Aronstam, D. L. Rickett, and E. X. Albuquerque (1984) The nature of the interactions of pyridostigmine with the nicotinic acetylcholine receptor-ionic channel complex. I. Agonist, desensitizing and binding properties. Mol. Pharmacol. 25: 92-101.

Rosenberry, T. (1979) Quantitative simulation of end-plate currents at neuromuscular junctions based on the reaction of acetylcholine with acetylcholine receptor and acetylcholinesterase. Biophys. J. 26: 263290.

Ruff, R. L. (1977) A quantitative analysis of local anaesthetic alteration of miniature end-plate currents and end-plate current fluctuations. J. Physiol. (Lond.) 264: 89-124.

Sine, S. M., and J. H. Steinbach (1984) Activation of a nictinic acetylcholine receptor. Biophys. J. 45: 175-185.

Takeuchi, A., and N. Takeuchi (1959) Active phase of frog's end-plate potential. J. Neurophysiol. 22: 395-411.

Trautman, A. (1983) A comparative study of the activation of the cholinergic receptor by various agonists. Proc. R. Soc. Lond. (Biol.) 218: 241-251.

Trautman, A., and S. A. Siegelbaum (1983) The influence of membrane patch isolation on single ACh channel current in rat myotubes. In Single Channel Recording, B. Sakmann and E. Neher, eds., pp. 473480, Plenum Press, New York.

Wathey, J. C., M. M. Nass, and H. A. Lester (1979) Numerical reconstruction of the quantal event at nicotinic synapses. Biophys. J. 27: 145-164.

White, R. L., and D. Gardner (1983) Physostygmine prolongs the elementary events underlying decay of inhibitory postsynaptic currents in Aplysia. J. Neurosci. 3: 2607-2613. 